Kajian Ekonomi Syariah

https://ejournal.iai-tribakti.ac.id/index.php/perbankan

\title{
Strategi Fundraising Dana Zakat Pada Lembaga Amil Zakat Nurul Hayat Kota Kediri
}

\section{Fundraising Strategy for Zakat Funds at Amil Zakat Institutions Nurul Hayat Kediri City}

\author{
Istiqomah $^{\mathbf{1}}$, Ahmad Fauzi ${ }^{2}$ \\ ${ }^{1}$ Institut Agama Islam Tribakti Kediri, ${ }^{2}$ Institut Agama Islam Tribakti Kediri \\ ${ }^{1}$ iisalvin080@gmail.com, ${ }^{2}$ ahmadfauzi007@gmail.com
}

\begin{abstract}
The collection (fundraising) of zakat funds is an effort or activity process in order to collect zakat funds and other resources from the community, both individuals, groups and organizations that will be distributed and used for mustahik. Fundraising activities require the right strategy in order to succeed the goals of fundraising effectively. There are several fundraising strategies that need to be considered, including: analyzing strengths, weaknesses, opportunities and threats. The right strategy has a big influence on the operation of zakat in every institution. The Amil Zakat Institution (LAZ) Nurul Hayat Kediri has an important role in collecting funds from the community and distributing it to the community. This research uses descriptive qualitative research methods and data sources come from the results of interviews and existing documents then analyzed using SWOT and then draw conclusions. Based on the results of the SWOT analysis carried out, LAZ Nurul Hayat Kediri is in an aggressive strategy position, namely the LAZ Nurul Hayat Kediri institution has opportunities and strengths so that it can take advantage of existing opportunities. Some of these strategies are: 1) increasing cooperation with DKM 2) providing scholarships to zakat study program students 3) introducing products to target customers 4) attracting muzakki from entrepreneurs.
\end{abstract}

Keywords: Fundraising Strategy, Zakat Fund

\begin{abstract}
Abstrak
Penghimpunan (fundraising) dana zakat merupakan suatu upaya atau proses kegiatan dalam rangka menghimpun dana zakat serta sumber daya lainnya dari masyarakat baik individu, kelompok, maupun organisasi yang akan disalurkan dan di dayagunakan
\end{abstract}




\section{Istiqomah, Ahmad Fauzi | Strategi Fundraising...}

untuk mustahik. Dalam kegiatan fundraising diperlukannya strategi yang tepat guna menyukseskan tujuan dari fundraising secara efektif. Ada beberapa strategi fundraising yang perlu diperhatikan antara lain: menganalisis kekuatan, kelemahan, peluang dan ancaman. Strategi yang tepat sangat berepengaruh besar terhadap jalannya zakat di setiap lembaga. Lembaga Amil Zakat (LAZ) Nurul Hayat Kediri memiliki peran penting dalam menghimpun dana dari masyarakat dan menyalurkan kepada masyarakat. Penelitian ini menggunakan metode penelitian kualitatif deskriptif dan sumber data berasal dari hasil wawancara dan dokumen-dokumen yang ada kemudian dianalisis menggunakan SWOT lalu ditarik kesimpulan. Berdasarkan hasil analisis SWOT yang dilakukan, LAZ Nurul Hayat Kediri berada pada posisi strategi agresif yaitu lembaga LAZ Nurul Hayat Kediri memiliki peluang dan kekuatan sehingga dapat memanfaatkan peluang yang ada. Beberapa strategi tersebut yaitu: 1) peningkatan kerjasama dengan DKM 2) memberikan beasiswa kepada mahasiswa prodi zakat 3) memperkenalkan produk ke target customer 4) menjaring muzakki dari kalangan pengusaha.

Kata Kunci : Strategi Fundraising, Dana Zakat

\section{Pendahuluan}

Zakat merupakan salah satu ibadah pokok yang wajib dijalankan oleh seluruh umat Islam, dimana zakat termasuk salah satu rukun Islam sebagaimana diungkapkan dalam Al-qur'an, sehingga keberadaannya dianggap sesuatu yang umum diketahui umat dan merupakan bagian mutlaq dari keislaman seseorang. Di dalam Al-Qur'an terdapat kurang lebih 27 ayat yang menjajarkan shalat dan kewajiban zakat dalam berbagai bentuk kata. ${ }^{1}$ Pada dasarnya hukum mengeluarkan zakat adalah wajib bagi setiap muslim yang telah memenuhi syarat dan ditetapkan dalam Al-Qur'an yaitu, sesuai dengan firman Allah SWT pada surat At-Taubah ayat 103 menyebutkan: "Ambillah zakat dari sebagian harta mereka, dengan zakat itu kamu

\footnotetext{
${ }^{1}$ Martavevi Azwar, Zakat Dan Kesejahteraan Sosial,\| Jurnal ISLAMINOMIC
} Vol. V, no. No. 2 (Agustus 2016): h. 62. 
membersihkan dan mensucikan mereka dan berdoalah untuk mereka. Sesungguhnya do'a kamu itu (menjadi) ketenteraman jiwa bagi mereka. Dan Allah Maha Mendengar lagi Maha Mengetahui" (QS. at-Taubah:103). ${ }^{2}$

Al-Qur'an menyatakan bahwa kesediaan berzakat dipandang sebagai indikator utama ketundukan seseorang terhadap ajaran agama Islam yang merupakan ciri utama seorang mukmin yang akan mendapat rahmat dan pertolongan Allat SWT. Kesediaan berzakat dipandang pula sebagai keinginan seseorang untuk membersihkan diri dan jiwanya dari berbagai sifat buruk seperti bakhil, egois, rakus dan tamak sekaligus berkeinginan untuk selalu membersihkan, mensucikan, dan mengembangkan harta yang dimilikinya.

Zakat juga memiliki peran yang signifikan dalam mengatasi berbagai permasalahan ekonomi. Zakat memiliki keunikan tersendiri karena terdapat dua dimensi, yaitu dimensi ketaatan kepada ALLAH SWT (hablum minallah) dan dimensi kepeduliaan terhadap sesama (hablum minannas). Adanya zakat juga diharapkan dapat meminimalisir kesenjangan pendapatan antara orang kaya dan orang miskin serta meningkatkan perekonomian. Dengan demikian, dana zakat memiliki potensi yang besar bagi kesejahteraan umat apabila dikelola secara tepat dan profesional.

Mengingat zakat begitu penting dan merupakan satu kewajiban bagi umat Islam. Serta dalam melaksanakan kewajiban zakat orang yang membayar (muzakki) tidak bisa terlepas dari urusan bersama, karena zakat berkaitan dengan harta benda dan kepada siapa harta itu akan diberikan. Maka pemerintahan Indonesia telah mengatur keberadaan organisasi pengelolaan zakat di Indonesia dalam peraturan perundang-undangan, yaitu Undang-Undang Nomor 38 Tahun 1999 dan keputusan Direktur Jenderal Bimbingan Masyarakat Islam dan Urusan Haji Nomor D/291 Tahun 2000

\footnotetext{
${ }^{2}$ Al-Qur'an, at-Taubah: 103.
} 


\section{Istiqomah, Ahmad Fauzi | Strategi Fundraising...}

tentang Teknis Pengelolaan Zakat. Peraturan perundang-undangan ini memuat aturan tentang pengelolaan yang terorganisir dengan baik, transparan dan profesional dilakukan oleh amil resmi yang ditunjuk oleh pemerintah yaitu Badan Amil Zakat (BAZ) dan Lembaga Amil Zakat (LAZ). ${ }^{3}$

Dengan tanda bukti adanya Undang-Undang Nomor 38 Tahun 1999 tentang Pengelolaan Zakat, kemudian diperbarui pada tahun 2011 yaitu Undang- Undang Nomor 23 Tahun 2011. Dijelaskan dalam undang-undang jika pengelolaan zakat dilaksanakan oleh dua lembaga yang sudah ada yaitu BAZ dan LAZ. Kedua lembaga ini memiliki peran yang penting dalam hal pengelolaan zakat, yang membedakan antara keduanya yaitu jika BAZ dibentuk oleh pemerintahan langsung, sedangkan LAZ dibentuk oleh masyarakat ataupun perkumpulan masyarakat yang memiliki tujuan yang sama yaitu menjadikan pengelolaan berjalan dengan baik dan sesuai dengan aturan maupun sesuai dengan syariah. Lembaga tersebut memiliki sebuah kegiatan yang sama sesuai dengan Undang-Undang yaitu meliputi kegiatan perencanaan, pengumpulan, pendistribusian dan pendahyagunaan. ${ }^{4}$

Untuk menentukan arah dan tujuan dalam pengelolaan zakat agar langkahnya dapat lebih produktif dan mempunyai nilai yang lebih, juga pengelola zakat bertujuan untuk meningkatkan efektivitas dan efesiensi pelayanan dalam pengelolaan zakat serta meningkatkan manfaat zakat yaitu mewujudkan kesejahteraan masyarakat. Maka diperlukan metode yang digunakan sebagai alat bantu mengelola dana zakat dengan baik, termasuk strategi dalam penghimpunan dana zakat (fundraising) dapat dikatakan selalu menjadi tema besar dalam organisasi amil zakat.

${ }^{3}$ Deni Lubis, Dedi Budiman Hakim, dan Yunita Hermawati Putri, -Mengukur Kinerja Pengelolaan Zakat Di Badan Amil Zakat Nasional (BAZNAS),\| JEBI (Jurnal Ekonomi dan Bisnis Islam) Vol. 3, no. No. 1 (Juni 2018): h. 2. h. 133

${ }^{4}$ Yusuf Wibisono, Mengelola Zakat Indonesia (Jakarta: Prenadamedia Group, 2015), 
Fundraising dapat diartikan sebagai suatu kegiatan menghimpun dana dan sumber daya lainnya dari masyarakat (baik individu, kelompok, organisasi, perusahaan atau pemerintah) yang mana dana tersebut akan disalurkan dan didayahgunakan untuk mustahik. Kegiatan fundraising merupakan kegiatan yang penting untuk diperhatikan. Dimana dengan fundraising yang baik, maka dana zakat yang terkumpul juga akan semakin optimal. $^{5}$ Dalam kegiatan fundraising setidaknya memiliki lima tujuan pokok, yaitu menghimpun dana, menghimpun donatur, menghimpun simpatisan atau pendukung, membangun citra lembaga (brand image), dan memberikan kepuasan pada donatur. ${ }^{6}$

Melihat masih banyaknya para pengusaha atau orang yang mempunyai harta yang lebih, dimana cara pembayaran zakatnya banyak yang belum terkoordinir. Hal ini dikarenakan masih minimnya tingkat kepercayaan masyarakat terhadap lembaga-lembaga pengelola zakat. Selain itu, sebagian umat muslim khususnya di Kediri belum mengerti cara menghitung zakat dan kepada siapa zakat akan diserahkan. Disertai faktor lainnya, bahwa mereka meyakini tidak akan ada sanksi apapun bagi yang tidak mengeluarkan zakat, karena pemahaman mereka yang masih belum mengerti tentang zakat sesuai syari'at. Sesuai dengan tujuan lahirnya badan atau lembaga amil zakat, seharusnya mampu menjadi sebuah harapan bagi para mustahik serta dapat terselesaikannya masalah kemiskinan dan pengangguran. Terlebih untuk negara di Indonesia sendiri yang mayoritas penduduknya beragama Islam, tentunya memiliki potensi yang besar dalam penerimaan zakat.

Dengan adanya fenomena yang terjadi menumbuhkan semangat umat

${ }^{5}$ Bella Permatasari, Pelaksanaan Fundraising Di Lembaga Amil Zakat Infak Dan Sedekah Muhammadiyah (Lazismu) Solo (Studi Berdasarkan Undang-Undang No 23 Tahun 2011)\| (PhD Thesis, IAIN Surakarta, 2018), h. 30.

${ }^{6}$ Atik Abidah, Analisis Strategi Fundraising Terhadap Peningkatan Pengelolaan Zis Pada Lembaga Amil Zakat Kabupaten Ponorogo,॥ Kodifikasia Vol. 10, no. No. 1 (Tahun 2016): h.169 


\section{Istiqomah, Ahmad Fauzi | Strategi Fundraising...}

muslim untuk membumikan syiar Islam, terkhususnya Lembaga Amil Zakat Nurul Hayat Kediri sebagai pengelola dana zakat dan penghubung antara nilai kepentingan muzakki dan mustahik. Untuk menambah potensi zakat khususnya di Kediri, tentu saja diperlukan strategi yang tepat bagi LAZ Nurul Hayat Kediri untuk mendapatkan hal tersebut.

Lembaga-lembaga zakat yang ada di kota Kediri mempunyai cara yang berbeda-beda dalam melakukan strategi penghimpunan dana zakat. Diantaranya dengan jemput zakat ke rumah-rumah muzakki, LAZ Nurul Hayat Kediri juga melakukan sosialisasi tentang sadar zakat kepada masyarakat, dengan seminar, survey, iklan, brosur, majalah, dan media lainnya yang memungkinkan para muzakki bisa cepat tanggap untuk segera membayarkan zakatnya. ${ }^{7}$

Dalam kegiatan fundraising, tentu dengan target penambahan jumlah dana zakat. Namun, peningkatan jumlah dana yang terkumpul diakibatkan oleh strategi fundraising perlu dianalisis kembali, apakah strategi fundraising ini dapat digunakan sehingga mempengaruhi kebijakan-kebijakan LAZ Nurul Hayat Kediri terhadap peningkatan jumlah donatur atau muzakki dalam menyalurkan dana zakatnya atau sebaliknya. Untuk menghasilkan strategi yang tepat adalah melalui analisis SWOT yang di kombinasikan dengan pendekatan BMC (Business model canvas).

Analisis SWOT menurut Freddy Rangkuti memiliki makna sebuah metode dari suatu rancangan strategi dalam berbagai bidang. Tujuannya untuk melakuakan evaluasi dari Strength (kekuatan), Weakness (Kelemahan), Opportunity (Kesempatan), Threat (Tantangan). ${ }^{8}$ Dalam menganalisis suatu strategi sebuah perusahaan dapat ditentukan oleh kombinasi faktor internal

\footnotetext{
${ }^{7}$ Agus Dwi Prasetyo, wawancara online Analisis SWOT strategi fundraising LAZ Nurul Hayat Kediri, 28 Mei 2020, Kantor Pusat LAZ Nurul Hayat Kediri.

8 Freddy Rangkuti, ANALISIS SWOT: Teknik Membedah Kasus Bisnis, Cet. 24 (Jakarta: PT. Gramedia Pustaka Utama, 2018), h. 19.
} 
dan faktor eksternal. Kedua faktor tersebut harus dipertimbangkan dalam analisis SWOT, sehingga mampu untuk mengidentifikasi sebuah strategi yang tepat untuk kedepannya.

Sedangkan Business model canvas (BMC) adalah kerangka kerja untuk mendefinisikan model bisnis dalam satu lembar kanvas. Model bisnis ini pertama kali diperkenalkan oleh Alexander Osterwalder dalam bukunya yang berjudul Business Model Generation. Dalam pendekatan BMC terdiri dari sembilan elemen yang mencakup customer segment, value proposition, channels, customer relationship,revenue streams, key activities, key resources, key partnership dan cost structure. ${ }^{9}$ Dalam pendekatan BMC tersebut, akan diidentifikasikan setiap komponennya secara detail yang kemudian akan di analisis menggunakan analisis SWOT. Penelitian ini bertujuan untuk merumuskan strategi penghimpunan (fundraising) dana zakat khususnya pada LAZ Nurul Hayat Kediri dengan analisis SWOT.

\section{Metode}

Berdasarkan permasalahan yang akan diteliti, maka peneliti menggunakan metode penelitian kualitatif. Pada penelitian ini, peneliti akan menggunakan metode penelitian Analisis Deskriptif. Penelitian ini melakukan observasi di Lembaga Amil Zakat (LAZ) Nurul Hayat yang berada di Jl. Penanggungan No. 64 Mojoroto Kota Kediri untuk melihat aktivitas langsung dari dekat. penulis mengadakan interview dengan pihak yang dianggap dapat memberikan penjelasan yang terkait dengan permasalahan yang diteliti yaitu dengan amil yang bekerja di Lembaga Amil Zakat (LAZ) Nurul Hayat Cabang Kediri.

\footnotetext{
${ }^{9}$ Dian Purnama Sari, Analisis Strategi Penghimpunan Zakat Dengan Pendekatan Business Model Canvas, „HUMAN FALAH: Jurnal Ekonomi dan Bisnis Islam”. Vol 1, no. 1 (2017): h. 261.
} 
Istiqomah, Ahmad Fauzi | Strategi Fundraising...

\section{Pembahasan}

\section{Mekanisme fundraising dana zakat pada LAZ Nurul Hayat Kediri}

a. Customer Segment (Segmentasi Konsumen)

Sebagai lembaga nirlaba maka pihak yang dikategorikan sebagai donatur atau pelanggan bagi LAZ Nurul Hayat Kediri adalah pihak yang membayar zakat atau muzakki, baik dari individu maupun organisasi atau perusahaan. Adapun segmentasi pelanggan LAZ Nurul Hayat Kediri adalah pasar massa. LAZ Nurul Hayat Kediri tidak membedabedakan antar segmen pelanggan yang berbeda. Sehingga saluran distribusi, hubungan pelanggan dan proposisi nilai berfokus pada kelompok besar pelanggan dengan kebutuhan dan masalah yang hampir sama.

b. Value Propositions (Proposisi Nilai Konsumen)

Value Proposition merupakan berbagai macam produk dan jasa yang akan menciptakan nilai bagi pelanggan segmen tertentu. Value adalah alasan mengapa pelanggan memilih produk dan jasa dari sebuah perusahaan dibandingkan perusahaan lain karena perusahaan tersebut dianggap memiliki kelebihan dalam memecahkan permasalahan dan memenuhi kebutuhan pelanggan. ${ }^{10}$

LAZ Nurul Hayat Kediri sendiri memiliki nilai proposisi terletakpada accessibility (kemampuan dalam mengakses) dengan adanya layanan aplikasi Muzakki Corner. Sehingga muzakki dapat dengan mudah mengecek dan mengontrol setoran zakat pada LAZ Nurul Hayat Kediri. Juga memiliki nilai proposisi terletak pada keunggulan layanan, yaitu memberikan layanan jemput zakat kepada muzakki. Hal ini tentunya memberikan kenyamanan bagi muzakki untuk membayar zakat dengan mudah dan efisien.

${ }^{10}$ Hendri Nugroho dan Dian Anubhakti, Analisa Dan Penerapan E-Commerce Pada Sporty Kuy Store Dengan Pendekatan Business Model Canvas, \| Jurnal IDEALIS Vol. 3, no. No. 1 (Januari 2020): h. 426. 
c. Channels (Saluran)

Dalam hal channels, pihak LAZ Nurul Hayat Kediri memiliki saluran sendiri untuk mendakwahkan zakat kepada masyarakat. Baik saluran yang dimiliki sendiri, maupun saluran yang bekerja sama dengan mitra. Di kantor LAZ Nurul Hayat Kediri terdapat konter khusus untuk membayar zakat. Beberapa muzakki memang lebih memilih untuk membayar zakat secara langsung di konter LAZ Nurul Hayat Kediri dengan harapan agar akad membayar zakatnya dilakukan secara langsung.

Dalam mendakwahkan zakat, LAZ Nurul Hayat Kediri mempunyai saluran melalui media-media online seperti facebook, twitter dan instagram, juga memalui brosur atau spanduk. Serta untuk memudahkan dalam menjangkau muzakki secara langsung, LAZ Nurul Hayat Kediri membuka seminar atau kajian di beberapa gerai maupun masyarakat.

Untuk memudahkan jangkauan muzakki dalam membayar zakat, LAZ Nurul Hayat Kediri menggunakan peranan perbankan guna mengikuti era digital sekarang. Masyarakat bisa melakukan pembayaran zakat via transfer perbankan, baik melalui mobile banking atau internet banking. Hal demikian sangat diminati muzakki yang berdomisili di kota- kota besar dengan kesibukan pekerjaan yang cukup padat.

d. Customer Relationships (Hubungan Konsumen)

Hubungan yang ingin dibangun bersama segmen pelanggan harus dijelaskan oleh suatu perusahaan tersebut, baik hubungan yang 


\section{Istiqomah, Ahmad Fauzi | Strategi Fundraising...}

bersifat pribadi sampai otomatis. ${ }^{11}$ Karena hubungan pelanggan yang diterapkan dalam model bisnis suatu perusahaan sangat mempengaruhi pengalaman pelanggan sacara keseluruhan.

LAZ Nurul Hayat Kediri berkomitmen menjaga silaturrahim dengan para muzakki dengan melakukan kunjungan serta memberikan gift tersendiri bagi muzakki yang melakukan donatur dengan jumlah yang besar. Selain untuk menjaga hubungan dan silaturrahim dengan para muzakki, LAZ Nurul Hayat Kediri mengadakan acara khusus bagi para muzakki untuk berkumpul dan bertemu. Pada kegiatan tersebut guna menyampaikan laporan penerimaan dan penyaluran zakat kepada para muzakki, baik muzakki perorangan maupun muzakki perusahan.

e. Revenue Streams (Sumber Pendapatan)

Dalam mekanisme penetapan besaran zakat, LAZ Nurul Hayat Kediri memberikan jasa dalam perhitungan besaran zakat kepada muzakki. Serta dana zakat yang terkumpul pada LAZ Nurul Hayat Kediri adalah dana amanah yang bukan menjadi miliknya. Sehingga pengelolaan dana zakat harus disesuaikan dengan ketentuan syari'ah.

f. Key Resources (Sumber Daya)

Setiap organisasi memerlukan sumber daya utama. Tak terkecuali LAZ Nurul Hayat Kediri. Sumber daya memungkinkan lembaga nirlaba untuk menciptakan dan menawarkan proposisi nilai, menjangkau pasar dan mempertahankan hubungan dengan muzakki. Bagi LAZ Nurul Hayat Kediri, sumber daya utama fisik yaitu kantor yang terletak di Jalan Penanggungan No. 64 Mojoroto Kota Kediri.

${ }^{11}$ Dian Purnamasari dan Achmad Firdaus, Analisis Strategi Penghimpunan Zakat Dengan Pendekatan Business Model Canvas, HUMAN FALAH Volume 4, no. No. 2 (Juli- Desember 2017): h. 268. 
Untuk menunjang operasional harian, peralatan komputer, jaringan internet, serta kendaraan operasional dan lainnya menjadi asset yang dibutuhkan. Sedangkan untuk sumber daya manusia, LAZ Nurul Hayat Kediri sangat memerlukan tenaga amil yang berkompeten di tiap bidang. Baik di bidang pengetahuan perzakatan, IT, akuntansi dan keuangan, design grafis, dan lainnya.

LAZ Nurul Hayat Kediri juga melakukan pendataan muzakki, untuk mengetahui kejelasan data para muzakki. Zakat yang dibayarkan oleh muzakki diakumulasikan secara keseluruhan dan disalurkan sesuai ketentuan syari'ah. Penyaluran zakat dilakukan berdasarkan pada data mustahik zakat yang masuk ke LAZ Nurul Hayat Kediri, seperti dari proposal masuk maupun laporan data mustahik dari masjid-masjid dan masyarakat.

Sementara untuk memastikan zakat dapat disalurkan kepada yang berhak menerimanya, maka lembaga melakukan survey terlebih dahulu kepada calon mustahik untuk memastikan kondisi mustahik yang akan menerima zakat tersebut.

g. Key Activites (Aktivitas Yang Dijalankan)

Dalam penelitian Osterwalder dan Pigner, elemen key activities menjelaskan aktivitas kunci berkaitan dengan hal-hal penting yang harus dilakukan oleh organisasi agar dapat beroperasi dengan sukses. Aktivitas kunci yang dijalankan LAZ Nurul Hayat Kediri adalah dengan melakukan sosialisasi zakat ke berbagai lini masyarakat, baik kepada perorangan maupun perusahaan. Sosialisasi juga dilakukan pada berbagai media sosial online seperti facebook dan instagram. LAZ Nurul Hayat Kediri juga menawarkan cara pembayaran zakat dengan langsung (direct) maupun tidak langsung (indirect).

Dana zakat yang terhimpun dari muzakki akan diakumulasi 


\section{Istiqomah, Ahmad Fauzi | Strategi Fundraising...}

secara keseluruhan dan disalurkan sesuai ketentuan syariah. Penyaluran zakat dilakukan berdasarkan pada data mustahik zakat yang sudah masuk pada pendataan LAZ Nurul Hayat Kediri, seperti dari laporan data mustahik dari masjid-masjid dan masyarakat. Dari pendataan tersebut akan dilakukan survey terhadap calon mustahik zakat untuk memastikan kondisi mustahik, sehingga zakat dapat disalurkan kepada yang berhak menerimanya.

h. Key Partnerships (Kerjasama)

Dalam menjalankan bisnis, sebuah perusahaan memiliki elemen utama dalam bermitra bisnis. ${ }^{12}$ Untuk mendukung dan mensponsori kegiatan yang diselenggarakan sebuah lembaga, Lembaga Amil Zakat Kediri telah menjalin kerja sama dan kemitraan bersama dengan beberapa perusahaan. LAZ Nurul Hayat Kediri selalu menjaga hubungan baik dengan mitra. Hubungan tersebut dibangun dengan komunikasi yang intens, melalui para amil di bagian Relationship Officer (RO) untuk menindaklanjuti setoran zakat yang telah dilakukan oleh muzakki melalui mitra.

i. Cost Structure (Struktur Biaya)

Elemen cost structure menggambarkan biaya terpenting yang muncul ketika mengoperasikan bisnis. Dalam hal ini, biaya yang muncul dalam mengelola zakat, baik dari proses penghimpunan hingga proses penyaluran. Karakteristik biaya yang dikeluarkan oleh LAZ Nurul Hayat Kediri adalah mencakup biaya tetap dan biaya variabel. Biaya tetap meliputi biaya sewa kantor, pembayaran gaji karyawan, perawatan kendaraan operasional, biaya listrik dan biaya

${ }^{12}$ Dian Purnamasari dan Achmad Firdaus, - Analisis Strategi Penghimpunan Zakat Dengan Pendekatan Business Model Canvas, HUMAN FALAH Volume 4, no. No. 2 (Juli- Desember 2017): h. 269. 
air. Sedangkan biaya variabel adalah biaya dalam pencetakan brosur dan buku, formulir, dan lain sebagainya.

\section{Strategi Fundraising zakat yang tepat dengan Analisis SWOT LAZ} Nurul Hayat Kediri

Dalam data ini, peneliti memperoleh dari pemimpin dan staf lembaga melalui wawancara, juga diperoleh melalui kuesioner kemudian dijustifikasi dalam bentuk bobot dan rating faktor pada Matriks SWOT. Dari hasil bobot dan rating tersebut akan digunakan untuk menentukan strategi fundraising zakat yang tepat bagi LAZ Nurul Hayat Kediri. Adapun responden diambil dari beberapa staf pada LAZ Nurul Hayat Kediri.

Tabel 1 Daftar Responden Penelitian

\begin{tabular}{|c|l|l|c|c|}
\hline No & \multicolumn{1}{|c|}{ Nama } & \multicolumn{1}{|c|}{ Jabatan } & L/P & Rentang usia \\
\hline 1 & Imam & Fundraiser & L & 26-35 tahun \\
\hline 2 & Anka & Admin & P & $15-25$ tahun \\
\hline 3 & Yasir Amin & ZA & L & 26-35 tahun \\
\hline 4 & Ayu & Admin ZIS & P & 26-35 tahun \\
\hline 5 & Imron Rosadi & Staff Program & L & 26-35 tahun \\
\hline
\end{tabular}

Bobot dan rating ditentukan berdasarkan pada isian kuesoiner. Acuan dari bobot dan rating adalah:

Tabel 2 Acuan Bobot dan Rating

\begin{tabular}{|c|c|c|c|}
\hline Bobot & Keterangan & Rating & Keterangan \\
\hline 0,20 & Sangat kuat & 4 & Major strength \\
\hline 0,15 & Di atas rata-rata & 3 & Minor strength \\
\hline 0,10 & Rata-rata & 2 & Minor weakness \\
\hline 0.05 & Di bawah rata-rata & 1 & Major weakness \\
\hline
\end{tabular}




\section{Istiqomah, Ahmad Fauzi | Strategi Fundraising...}

Setelah mengelompokkan kekuatan, kelemahan, peluang dan ancaman LAZ Nurul Hayat Kediri, selanjutnya dianalisis dengan menggunakan SWOT yang dapat menghasilkan kemungkinan alternatif strategi pengelolaan zakat, khususnya dalam sisi penghimpunan dana zakat. Selain memperhatikan faktor- faktor di atas, dari kekuatan kelemahan (faktor internal) dan peluang ancaman (faktor eksternal) dalam upaya pengembangan strategi LAZ Nurul Hayat Kediri dapat disusun Internal Factor Analysis Summary (IFAS) dan External Factor Analysis Summary (EFAS) untuk menentukan strategi penghimpunan dana zakat yang akan digunakan. ${ }^{13}$

a. Tahapan menentukan matriks Internal Factor Analysis Summary (IFAS)

(1) Susun dalam kolom 1 (faktor yang menjadi kekuatan serta kelemahan perusahaan)

(2) Beri bobot dalam kolom 2, mulai dari 0,20 sangat kuat sampai 0,05

(3) Bari rating pada kolom 3 dengan memberi skala 4 (outstanding) sampai dengan 1 (poor) untuk faktor kekuatan bersifat positif. Sedangkan pemberian rating untuk kelemahan kebalikannya, 1 sangat penting sampai 4 sangat tidak penting.

(4) Kalikan bobot pada kolom 2 dengan rating pada kolom 3, untuk memperoleh faktor pembobotan dalam kolom 4.

Jumlahkan skor pada kolom 4 untuk memperoleh total skor. Nilai total skor ini menunjukkan bagaimana perusahaan tertentu bereaksi terhadap faktor-faktor strategis eksternalnya.

\footnotetext{
${ }^{13}$ Rangkuti, ANALISIS SWOT: Teknik Membedah Kasus Bisnis, h. 25.
} 
Adapun faktor IFAS dalam penelitian ini sebagai berikut:

Tabel 3 Internal Factor Analysis Summary (IFAS)

\begin{tabular}{|c|c|c|c|c|c|}
\hline & Faktor Internal & Bobo & Rating & Skor & Keterangan \\
\hline & 1. Jumlah muzakki & 0,14 & 4 & 0,57 & Mencerminkan \\
\hline & $\begin{array}{l}\text { 2. Lembaga } \\
\text { memiliki legalitas }\end{array}$ & 0,10 & 3 & 0,29 & $\begin{array}{l}\text { Sebagai upaya } \\
\text { perlindungan hukum }\end{array}$ \\
\hline 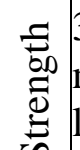 & $\begin{array}{l}\text { 3. Kepuasan } \\
\text { muzakki terhadap } \\
\text { layanan }\end{array}$ & 0,14 & 2 & 0,29 & $\begin{array}{l}\text { Meningkatkan } \\
\text { kepercayaa pelanggan }\end{array}$ \\
\hline & $\begin{array}{l}\text { 4. Sumber Daya } \\
\text { Insani yang mumpuni }\end{array}$ & 0,10 & 3 & 0,29 & $\begin{array}{l}\text { Kelancaran kinerja } \\
\text { terjamin }\end{array}$ \\
\hline & $\begin{array}{l}\text { 5. Dana zakat } \\
\text { amanah }\end{array}$ & 0,14 & 3 & 0,43 & $\begin{array}{l}\text { Wujud tanggungjawab } \\
\text { menjaga amanah }\end{array}$ \\
\hline & Sub total & 0,62 & & 1,86 & \\
\hline & $\begin{array}{l}\text { 1. Belum adanya } \\
\text { kartu muzakki }\end{array}$ & 0,10 & 1 & 0,10 & $\begin{array}{l}\text { Pengklasifikasian } \\
\text { muzakki kurang } \\
\text { optimal }\end{array}$ \\
\hline$\ddot{\delta}^{t}$ & $\begin{array}{l}\text { 2. Jumlah onter } \\
\text { terbatas }\end{array}$ & 0,05 & 1 & 0,05 & $\begin{array}{l}\text { Dana terhimpun belum } \\
\text { maksimal }\end{array}$ \\
\hline$\sum_{1}^{\frac{5}{D}}$ & $\begin{array}{l}\text { memaksimalkan } \\
\text { kerjasama dengan } \\
\text { instantsi } \\
\text { pemerintah }\end{array}$ & 0,10 & 2 & 0,19 & $\begin{array}{l}\text { Belum dapat } \\
\text { menjaring semua } \\
\text { potensi dari instansi }\end{array}$ \\
\hline & $\begin{array}{l}\text { 4. Sarana prasarana } \\
\text { belum memadai }\end{array}$ & 0,14 & 2 & 0,29 & $\begin{array}{l}\text { Hambatan dalam } \\
\text { kinerja }\end{array}$ \\
\hline & Sub total & 0,38 & & 0,62 & \\
\hline & TOTAL & 1,00 & & 2,48 & \\
\hline
\end{tabular}

Berdasarkan hasil penelitian Mei 2020 pada analisis matriks IFAS bahwa nilai kekuatan lebih tinggi dengan jumlah 1,86 dibandingkan dengan nilai kelemahan yakni dengan jumlah 0,62 . 
Istiqomah, Ahmad Fauzi | Strategi Fundraising...

b. Tahapan menentukan matrik Eksternal Factor Analysis Summary (EFAS)

(1) Susun dalam kolom 1 (faktor peluang dan ancaman)

(2) Beri bobot dalam kolom 2, mulai 0,20 sangat kuat sampai 0,05 di bawah rata-rata

(3) Beri rating pada kolom 3 untuk masing-masing memberi skala 4 sangat penting sampai 1 sangat tidak penting untuk pemberian rating faktor peluang. Sedangkan untuk pemberian rating faktor ancaman kebalikannya, 1 sangat penting sampai 4 sangat tidak penting.

(4) Kalikan bobot pada kolom 2 dengan rating pada kolom 3, untuk memperoleh faktor pembobotan dalam kolom 4 .

(5) Jumlahkan skor pada kolom 4 untuk memperoleh total skor. Nilai total skor ini menunjukkan bagaimana perusahaan tertentu bereaksi terhadap faktor-faktor strategis eksternalnya.

Adapun faktor EFAS dalam penelitian ini sebagai berikut:

Tabel 4 Eksternal Factor Analysis Summary (EFAS)

\begin{tabular}{|c|c|c|c|c|c|}
\hline & Faktor Eksternal & Bobot & Ratins & Skor & Keterangan \\
\hline \multirow{6}{*}{ 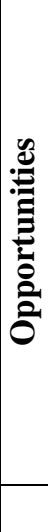 } & 1. Bekerjasama dengan & 0,17 & 3 & 0,50 & Peluang muzakki dari \\
\hline & $\begin{array}{l}\text { organisas1 keagamaan } \\
\text { 2. Dibukanya prodi }\end{array}$ & 0,17 & & 0,67 & $\begin{array}{l}\text { masyarakat umum } \\
\text { Mendukung }\end{array}$ \\
\hline & $\begin{array}{l}\text { dan konsentrasi zakat } \\
\text { di Perguruan Tinggi }\end{array}$ & & & & \\
\hline & $\begin{array}{l}\text { 3. Perkembangan ICT } \\
\text { semakin pesat }\end{array}$ & 0,11 & 3 & & $\begin{array}{l}\text { Mitra dalam } \\
\text { penghimpunan zakat }\end{array}$ \\
\hline & $\begin{array}{l}\text { 4. Masih banyak } \\
\text { Pembayaran zakat } \\
\text { belum terkoordinir }\end{array}$ & 0,17 & 2 & 0,33 & $\begin{array}{l}\text { Peluang besar belum } \\
\text { tergarap maksimal }\end{array}$ \\
\hline & Sub total & 0,61 & & & \\
\hline
\end{tabular}




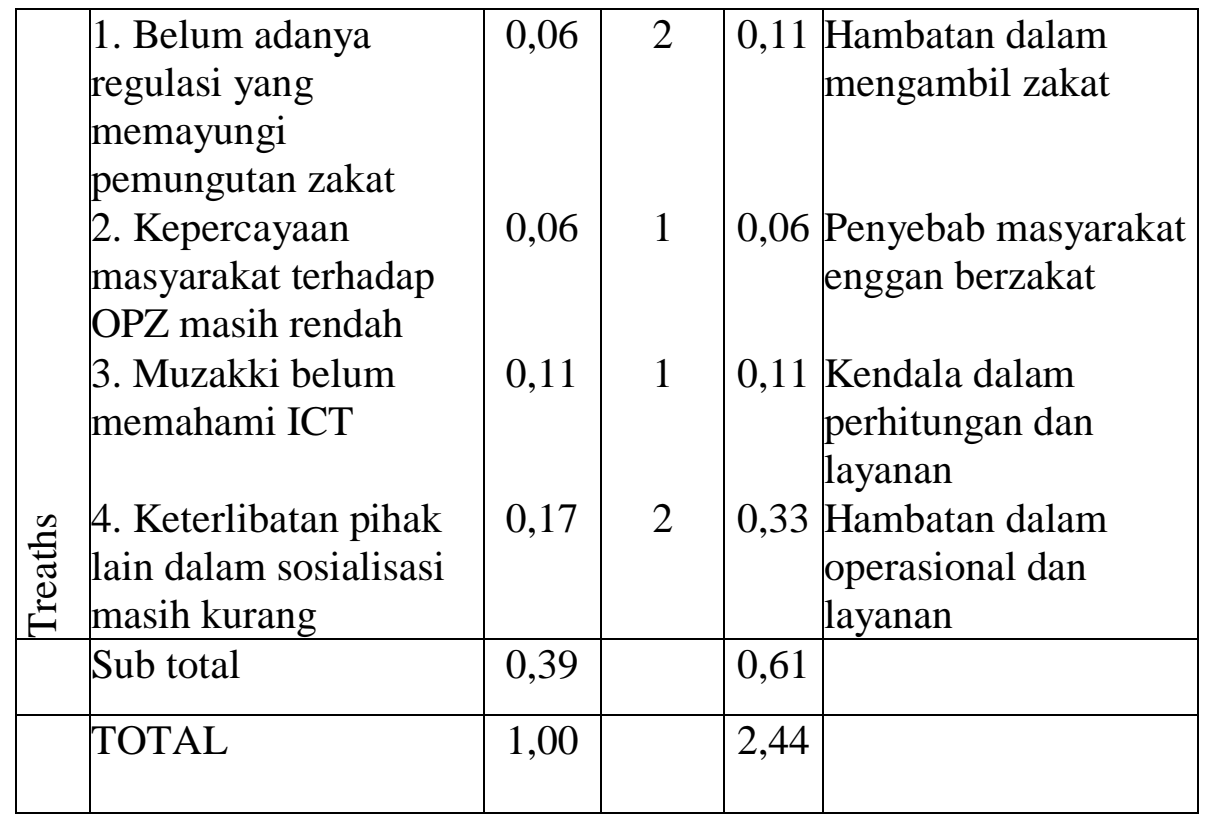

Berdasarkan hasil analisis yang dilakukan oleh peneliti pada matriks EFAS bahwa nilai tertinggi terdapat pada peluang dengan jumlah 1,83 sedangkan untuk nilai ancaman dengan jumlah 0,61.

Setelah mengetahui hasil penelitian pada tabel IFAS dan EFAS dari LAZ Nurul Hayat Kediri, maka tahap selanjutnya melakukan penjumlahan selisih matriks IFAS dan EFAS untuk menentukan keputusan strategi alternatif, berikut tabel penjumlahan:

Tabel 5 Penjumlahan IFAS dan EFAS

\begin{tabular}{|l|l|l|}
\hline \multicolumn{1}{|c|}{ IFAS } & \multicolumn{1}{c|}{ EFAS } & \multicolumn{1}{c|}{ Total } \\
\hline Kekuatan $(\mathrm{S})=1,86$ & Peluang $(\mathrm{O})=1,83$ & $\mathrm{~S}+\mathrm{O}=3,69$ \\
\hline Kelemahan $(\mathrm{W})=$ & Ancaman $(\mathrm{T})=$ & $\mathrm{W}+\mathrm{T}=1,23$ \\
0,62 & 0,61 & \\
\hline $\mathrm{S}-\mathrm{W}=1,24$ & $\mathrm{O}-\mathrm{T}=1,22$ & \\
\hline
\end{tabular}

Dari rumus hasil tersebut akan didapatkan koordinat satu titik, dimana titik itulah yang menentukan kedudukan perusahaan dalam analisis SWOT, yaitu sumbu $x=1,24$ dan sumbu $y=1,22$. Dapat 
dilihat pada Gambar berikut:

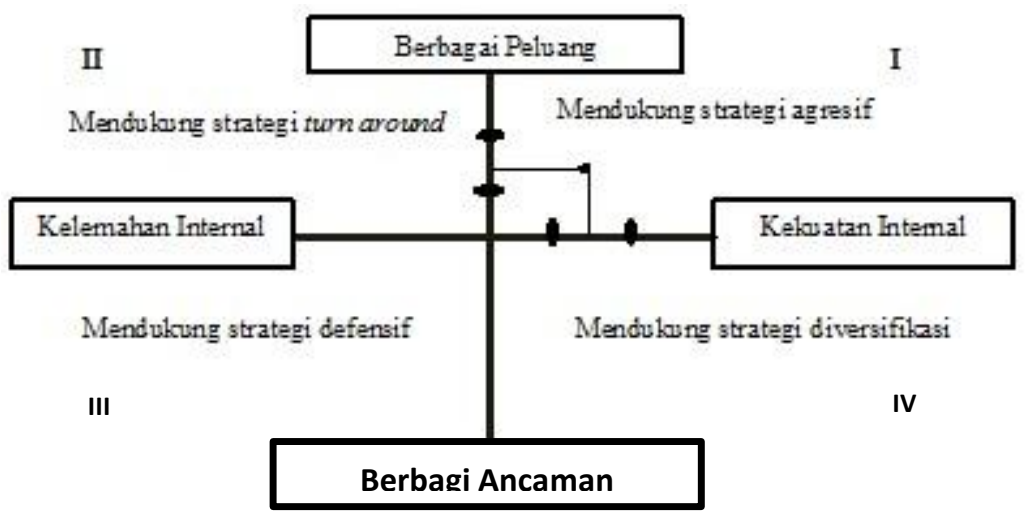

\section{Gambar 1 Kuadran SWOT}

Penjelasan :

1. Kuadran I : merupakan situasi yang sangat menguntungkan. Perusahaan tersebut memiliki peluang dan kekuatan sehingga dapat memanfaatkan peluang yang ada. Strategi yang harus diterapkan dalam kondisi ini adalah mendukung kebijakan pertumbuhan yang agresif.

2. Kuadarn II : Posisi ini menandakan sebuah organisasi atau lembaga yang lemah namun sangat berpeluang. Rekomendasi strategi yang diberikan adalah meminimalkan masalah-masalah internal organisasi atau lembaga sehingga dapat merebut peluang.

3. Kuadran III : Posisi ini menandakan sebuah organanisasi atau lembaga yang lemah dan menghadapi tantangan besar. Rekomendasi strategi yang diberikan adalah strategi bertahan, yaitu mengendalikan kinerja internal agar tidak semakin terperosok. Strategi ini dipertahankan sambil terus berupaya membenahi diri. 
4. Kuadran IV : Posisi ini menandakan sebuah organisasi atau lembaga yang kuat namun menghadapi tantangan yang besar. Rekomendasi strategi yang diberikan adalah Diversifikasi Strategi, dengan kata lain perlu strategi yang lainnya menjadi lebih beragam atau tidak terpalu hanya pada satu strategi saja. Komponen berada pada situasi mantap namun juga menghadapi sejumlah tantangan. Sehingga diperkirakan penanganannya akan mengalami kesulitan jika hanya bergantung pada satu strategi.

Pilihan strategi yang harus dilakukan LAZ Nurul Hayat Kediri merujuk pada perbandingan nilai IFAS dan EFAS. Kuadran I, nilai S $(1,86)>\mathrm{O}(1,83)$. Kuadran II, nilai $\mathrm{O}(1,83)>\mathrm{W}(0,63)$. Kuadran III, nilai $\mathrm{T}(0,61)<\mathrm{W}(0,62)$. Kuadran IV, nilai $\mathrm{S}(1,86)>\mathrm{T}(0,61)$. Dengan demikian pilihan strategi yang efektif diterapkan oleh LAZ Nurul Hayat Kediri adalah: Strategi SO (kuadran I) bersifat pertumbuhan bertahap. Sedangkan Strategi WO (kuadran II) bersifat mempertahankan peran secara agresif. Strategi WT (kuadran III) bersifat mencari peluang. Strategi ST (kuadran IV) bersifat diversifikasi secara luas ke berbagai kegiatan.

Kemudian untuk menyusun faktor-faktor sebagi alternatif usaha ini dan dapat menggambarkan dengan jelas, Maka dengan Matrik SWOT dapat mempermudah menentukan strategi yang tepat untuk usaha ini. Berikut alternatif strategi menggunakan matrik SWOT untuk meningkatkan potensi fundraising zakat pada LAZ Nurul Hayat Kediri. 
Istiqomah, Ahmad Fauzi | Strategi Fundraising...

Tabel 4.8 Matrik SWOT LAZ Nurul Hayat Kediri

\begin{tabular}{|c|c|c|}
\hline & Kekuatan (S) & Kelemahan (W) \\
\hline & $\begin{array}{l}\text { 1. Retensi muzakki } \\
\text { bertambah } \\
\text { 2. Memiliki Legalitas } \\
\text { 3. Tingkat kepuasan } \\
\text { muzakki tinggi } \\
\text { 4. SDI mumpuni }\end{array}$ & $\begin{array}{l}\text { 1. Belum adanya kartu } \\
\text { muzakki } \\
\text { 2. Konter terbatas } \\
\text { 3. Belum maksimal } \\
\text { kerjasama dengan } \\
\text { instansi dan lembaga } \\
\text { pemerintah } \\
\text { 4. Sarana prasarana } \\
\text { belum memadai }\end{array}$ \\
\hline Peluang (O) & $\begin{array}{l}\text { (Strategi SO) } \\
\text { Gunakan kekuatan untuk } \\
\text { memanfaatkan peluang }\end{array}$ & $\begin{array}{l}\text { (Strategi WO) } \\
\text { Atasi kelemahan dengan } \\
\text { memanfaatkan peluang }\end{array}$ \\
\hline $\begin{array}{l}\text { 1. Bekerj } \\
\text { asama } \\
\text { dengan } \\
\text { organisasi } \\
\text { keagamaan } \\
2 . \quad \text { Dibuk } \\
\text { anya prodi } \\
\text { dan } \\
\text { konsentrasi } \\
\text { zakat di } \\
\text { Perguruan } \\
\text { Tinggi } \\
3 . \quad \text { Perke } \\
\text { mbangan } \\
\text { ICT } \\
4 . \quad \text { Pemba } \\
\text { yaran belum } \\
\text { terkoordinir }\end{array}$ & $\begin{array}{l}\text { 1. Peningkatan kerjasama } \\
\text { dengan DKM } \\
\text { 2. Memberikan beasiswa } \\
\text { kepada mahasiswa } \\
\text { prodi zakat } \\
\text { 3. Memperkenalkan } \\
\text { produk ke target } \\
\text { customer rr muzakki } \\
\text { 4. Menjaring } \begin{array}{l}\text { Mariangan } \\
\text { dari } \\
\text { pengusaha }\end{array}\end{array}$ & $\begin{array}{l}\text { 1. Peningkatan konter } \\
\text { zakat di lokasi } \\
\text { strategis, baik di } \\
\text { lembaga pemerintah } \\
\text { maupun keagamaan } \\
\text { 2. } \begin{array}{l}\text { Menyampaikan } \\
\text { sosialisasi zakat secara } \\
\text { rutin lewat berbagai } \\
\text { forum dan acara }\end{array}\end{array}$ \\
\hline Ancaman (T) & $\begin{array}{l}\text { (Strategi ST) } \\
\text { Gunakan kekuatan untuk } \\
\text { menghindari ancaman }\end{array}$ & $\begin{array}{l}\text { (Strategi WT) } \\
\text { Meminimalkan kelemahan } \\
\text { dan menghindari ancaman }\end{array}$ \\
\hline
\end{tabular}




\begin{tabular}{|c|c|c|}
\hline $\begin{array}{l}1 . \quad \text { Belum } \\
\text { adanya } \\
\text { regulasi } \\
\text { yang } \\
\text { memayungi } \\
\text { pemungutan } \\
\text { zakat } \\
2 . \quad \text { Keper } \\
\text { cayaan } \\
\text { masyarakat } \\
\text { masih } \\
\text { rendah } \\
3 . \quad \text { Muzak } \\
\text { ki belum } \\
\text { memahami } \\
\text { ICT } \\
4 . \quad \text { Keterli } \\
\text { batan pihak } \\
\text { lain dalam } \\
\text { bersosialisas } \\
\text { i }\end{array}$ & $\begin{array}{l}\text { 1. Mendorong pemerintah } \\
\text { untuk mendukung } \\
\text { optimalisasi } \\
\text { penghimpunan zakat } \\
\text { 2. Mengembangkan } \\
\text { sistem ICT untuk } \\
\text { optimalisasi } \\
\text { penghimpunan dan } \\
\text { pelaporan zakat }\end{array}$ & 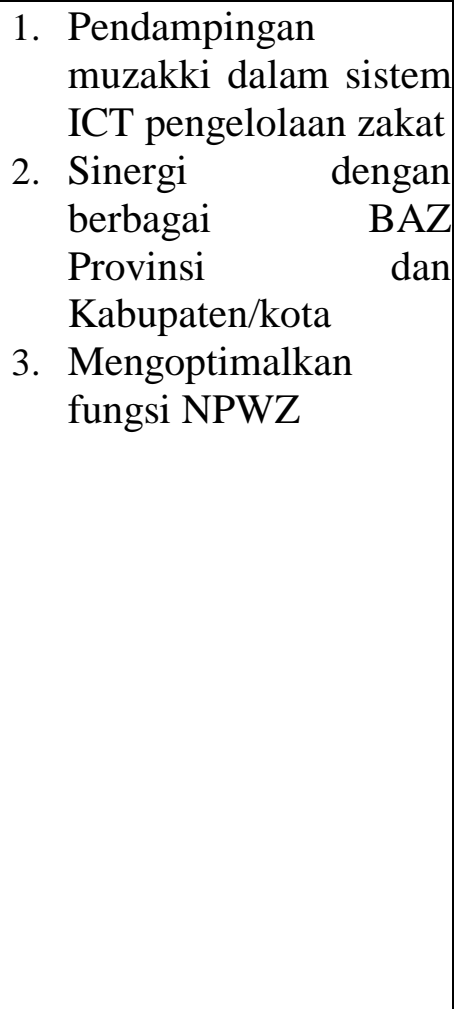 \\
\hline
\end{tabular}

Berdasarkan matrik SWOT di atas menunjukkan bahwa kinerja LAZ Nurul Hayat Kediri dapat di kombinasikan yakni kekuatan, kelemahan, peluang dan ancaman sehingga dapat ditarik kesimpulan oleh pemilik LAZ Nurul Hayat Kediri untuk mengambil keputusan strategi fundraising yang efektif.

Strategi SO dirumuskan dengan pertimbangan bahwa manajemen hendak memanfaatkan kekuatan lembaga dan keunggulan layanan yang dimiliki untuk mengeksploitasi peluang yang ada. Sebagaimana lokasi LAZ Nurul Hayat Kediri yang dekat dengan dengan lingkungan pesantren, hal tersebut menjadi sangat potensial bagi LAZ Nurul Hayat Kediri untuk bekerjasama dengan DKM (Dewan Kemakmuran Masjid) maupun pesantren dalam menghimpun zakat. 


\section{Istiqomah, Ahmad Fauzi | Strategi Fundraising...}

Strategi memberikan beasiswa atau berpartisipasi kepada para mahasiswa khususnya dari Program Studi atau Konsentrasi zakat dan wakaf. Beasiswa yang diberikan kepada mahasiswa selain sebagai kegiatan pemberdayaan mahasiswa (program pendistribusian zakat) juga dapat mempersiapkan calon talenta zakat. Talenta diharapkan mampu mengembangkan program zakat menjdai lebih baik dibandingkan dengan yang sudah dilakukan.

LAZ Nurul Hayat Kediri dapat menghimpun zakat dari kalangan pengusaha. Himpunan pengusaha di Kediri terdapat 49.962 pengusaha. ${ }^{14}$ Angka menunjukkan potensi yang sangat besar untuk menghimpun dana zakat.

Juga memperkenalkan produk atau jasa layanan yang dimiliki LAZ Nurul Hayat Kediri kepada masyarakat melalui media sosial yang saat ini sedang berkembang pesat, seperti whatsapp, facebook, twitter, instagram, dan lain sebagainya.

Strategi WO dilakukan untuk memanfaatkan peluang yang tersedia dengan mengeliminasi kelemahan lembaga. LAZ Nurul Hayat Kediri perlu menambah jumlah konter zakat di lokasi-lokasi yang dinilai strategis baik di Lembaga atau instansi pemerintah maupun di masjid-masjid. Jumlah masjid di kota Kediri sendiri tercata sekitar 21 Masjid Jami` dan Masjid di tempat publik. ${ }^{15}$ Tentu saja menjadi potensi luar biasa dalam menghimpun zakat. Dengan diadakan sosialisasi tentang zakat kepada masyarakat terus-menerus digalakkan, seperti forum pengajian majlis ta'lim, khutbah jum'at, seminar, perayaan hari raya, dll, adalah media yang cukup efektif

\footnotetext{
${ }^{14}$ Badan Pusat Statistik Kota Kediri, Statistik Angkatan Kerja Kota Kediri Tahun 2019 (Kediri: BPS Kota Kediri, 2019.), h. 46.

${ }^{15}$ Daftar Masjid / Musholla Di Kota Kediri, Jawa Timur | Profil Masjid / Musholla,\| Dream.co.id, diakses 17 Juli 2020, https://www.dream.co.id/.
} 
untuk mensosialisasikan zakat.

Strategi ST dilakukan dengan memanfaatkan kekuatan yang dimiliki untuk menghindari efek negatif ancaman dari luar. Sebagai rekomendasi yang diajukan dalam strategi ini adalah pihak LAZ Nurul Hayat Kediri sebagai lembaga nirlaba dan mandiri perlu mendorong instansi atau lembaga pemerintah untuk mendukung optimalisasi penghimpunan (fundraising) zakat. Hal tersebut dapat dilakukan dengan mendorong untuk dikeluarkannya berbagai perangkat aturan dan perundang-undangan yang dapat mendorong optimalisasi penghimpunan dana zakat. Sebagai contoh yang dapat diajukan adalah peraturan yang mengatur posisi zakat disamakan dengan pajak.

Dalam strategi ini juga terdapat rekomendasi kepada pihak LAZ Nurul Hayat Kediri untuk mengembangkan sistem ICT. Karena tidak dipungkiri bahwa di era digital seperti ini, ICT memegang peranan yang sangat penting. Hal tersebut juga akan sangat mendukung dalam optimalisasi penghimpunan (fundraising) dana zakat dan pelaporan pengelolaan zakat kepada masyarakat.

Strategi WT pada dasarnya lebih merupakan strategi bertahan yaitu strategi bisnis yang masih bisa ditemukan dan dipilih dengan meminimalisasi kelemahan dan menghindari ancaman dari luar. Hal tersebut dapat dilakukan oleh LAZ Nurul Hayat Kediri dengan mengadakan pendampingan muzakki dalam sistem ICT terkait zakat. Karena masih terdapat beberapa kalangan dari muzakki yang tidak ingin susah dengan perangkat ICT dalam berzakat. Mereka lebih memilih hal yang mudah dan nyaman. Maka terkait hal ini, LAZ Nurul Hayat Kediri perlu melakukan berbagai penyampaian informasi dan meng- update segala informasi kepada muzakki melalui berbagai media. 


\section{Istiqomah, Ahmad Fauzi | Strategi Fundraising...}

Di sisi lain, pihak LAZ Nurul Hayat Kediri juga bisa mengoptimalisasikan NPWZ (Nomor Pokok Wajib Zakat), sehingga mempermudah muzakki untuk mengakses pembayaran zakat, hal tersebut juga sebagai database penyetor zakat. Juga perlu untuk bersinergi kepada instansi atau lembaga pemerintah agar sebuah koordinasi lebih terintegratif sehingga dapat menjaga profesionalisme dan akuntabilitasnya sebuah lembaga.

Dari hasil tersebut penjumlahan IFAS dan EFAS diatas bahwa jumlah SO sebesar 3,69 lebih besar dari pada jumlah WT yaitu sebesar 1,23. Maka strategi fundraising zakat yang tepat bagi LAZ Nurul Hayat Kediri untuk meningkatkan potensi zakat adalah memanfaatkan peluang dan kekuatan yang ada dalam LAZ Nurul Hayat Kediri tersebut.

\section{Kesimpulan}

Mekanisme fundraising zakat pada LAZ Nurul Hayat Kediri saat ini dengan dijabarkan dalam Business Model Canvas (BMC). (a) Customer Segment, LAZ Nurul Hayat Kediri menghimpun dana zakat dari semua kalangan, baik muzakki individu maupun perorangan. (b) Value proposition, LAZ Nurul Hayat Kediri memberikan pelayanan yang unggul kepada para muzakki dengan jemput zakat, yaitu mengambil zakat dengan mendatangi secara langsung kepada muzakki. (c) Channels, LAZ Nurul Hayat Kediri memiliki konter khusus untuk menerima zakat yang bertempat di kantor pusat LAZ Nurul Hayat Kediri. Juga dalam mendakwahkan zakat memiliki saluran melalui media online, dan brosur. (d) Customer Relationships, Untuk menjalin hubungan dengan para muzakki, LAZ Nurul Hayat Kediri membuat sebuah perkumpulan atau grub para muzakki dengan memiliki tujuan konsultasi masalah zakat. (e). Revenue Streams, dalam pengelolaannya LAZ 
Nurul Hayat Kediri berpinsip bahwa dana zakat merupakan dana amanah. (f). Key Resource, semua asset LAZ Nurul Hayat menjadi sumber daya utama untuk menunjang kinerja operasional harian. (f) Key Activies, dengan menjalankan sosialisasi secara langsung maupun tidak langsung. (g). Key Partnership, dengan membangun komunikasi yang intens dengan mitranya. (h). Cost Structure, biaya yang dikeluarkan mencakup biaya tetap dan biaya variabel.

Strategi fundraising (penghimpunan) dana zakat pada LAZ Nurul Hayat Kediri meliputi:

a. Peningkatan kerjasama dengan berbagai instansi, termasuk instansi pemerintah.

b. Menambah frekuensi sosialisasi melalui pelaksanaan seminar dan workshop zakat maupun media sosial.

c. Memberikan beasiswa atau berpartisipasi kepada mahasiswa di program studi yang menjurus zakat.

d. Menjaring muzakki dari kalangan pengusaha yang banyak pembayarannya belum terkoordinir.

e. Mengoptimalkan pemfungsian NPWZ.

\section{Daftar Pustaka}

Abidah, Atik, Analisis Strategi Fundraising Terhadap Peningkatan Pengelolaan Zis Pada Lembaga Amil Zakat Kabupaten Ponorogo,\| Kodifikasia Vol. 10, no. No. 1 (Tahun 2016)

Al-Qur'an, at-Taubah: 103.

Azwar, Martavevi , Zakat Dan Kesejahteraan Sosial,\| Jurnal ISLAMINOMIC Vol. V, no. No. 2 (Agustus 2016).

Badan Pusat Statistik Kota Kediri, Statistik Angkatan Kerja Kota Kediri Tahun 2019 (Kediri: BPS Kota Kediri, 2019) 
Istiqomah, Ahmad Fauzi | Strategi Fundraising...

Daftar Masjid / Musholla Di Kota Kediri, Jawa Timur |Profil Masjid / Musholla,\| Dream.co.id, diakses 17 Juli 2020, https://www.dream.co.id/.

Lubis, Deni, Dedi Budiman Hakim, dan Yunita Hermawati Putri, -Mengukur Kinerja Pengelolaan Zakat Di Badan Amil Zakat Nasional (BAZNAS),\| JEBI (Jurnal Ekonomi dan Bisnis Islam) Vol. 3, no. No. 1 (Juni 2018)

Nugroho, Hendri dan Dian Anubhakti, Analisa Dan Penerapan ECommerce Pada Sporty Kuy Store Dengan Pendekatan Business Model Canvas,\| Jurnal IDEALIS Vol. 3, no. No. 1 (Januari 2020)

Permatasari, Bella, Pelaksanaan Fundraising Di Lembaga Amil Zakat Infak Dan Sedekah Muhammadiyah (Lazismu) Solo (Studi Berdasarkan Undang-Undang No 23 Tahun 2011)॥ (PhD Thesis, IAIN Surakarta, 2018)

Prasetyo, Agus Dwi, wawancara online Analisis SWOT strategi fundraising LAZ Nurul Hayat Kediri, 28 Mei 2020, Kantor Pusat LAZ Nurul Hayat Kediri.

Purnamasari, Dian dan Achmad Firdaus, Analisis Strategi Penghimpunan Zakat Dengan Pendekatan Business Model Canvas,\| HUMAN FALAH Volume 4, no. No. 2 (Juli- Desember 2017)

Purnamasari, Dian dan Achmad Firdaus, -Analisis Strategi Penghimpunan Zakat Dengan Pendekatan Business Model Canvas,\| HUMAN FALAH Volume 4, no. No. 2 (Juli- Desember 2017)

Rangkuti, Freddy, ANALISIS SWOT: Teknik Membedah Kasus Bisnis, Cet. 24 (Jakarta: PT. Gramedia Pustaka Utama, 2018)

Sari, Dian Purnama , Analisis Strategi Penghimpunan Zakat Dengan Pendekatan Business Model Canvas,\| HUMAN FALAH: Jurnal Ekonomi dan Bisnis Islam”. Vol 1, no. 1 (2017)

Wibisono, Yusuf, Mengelola Zakat Indonesia (Jakarta: Prenadamedia Group, 2015) 